\title{
Interactions between progesterone and tumor necrosis factor- $\alpha$ in the regulation of primordial follicle assembly
}

\author{
Eric E Nilsson, Jacob Stanfield and Michael K Skinner \\ School of Molecular Biosciences, Center for Reproductive Biology, Washington State University, Pullman, \\ Washington 99164-4231, USA \\ Correspondence should be addressed to M K Skinner; Email: skinner@wsu.edu
}

\begin{abstract}
Follicle assembly is the process by which groups or 'nests' of oocytes break down to form primordial follicles. The size of the primordial follicle pool is the major determinant of the reproductive lifespan of a female. Previously, progesterone $\left(\mathbf{P}_{4}\right)$ has been shown to inhibit follicle assembly, while tumor necrosis factor- $\alpha$ (TNF $\alpha$ ) has been shown to promote the apoptosis that is necessary for follicle assembly. The present study examines how TNF $\alpha$ and progesterone interact to regulate primordial follicle assembly. Ovaries were collected from newborn rats and placed in organ culture to examine the actions of $P_{4}$ and TNF $\alpha$. $P_{4}$ was found to decrease primordial follicle assembly and increase the percentage of unassembled oocytes both in vitro and in vivo.

TNF $\alpha$ treatment did not change the proportion of assembled follicles in cultured ovaries, but blocked the ability of $\mathbf{P}_{\mathbf{4}}$ to inhibit follicle assembly. Microarray analysis of the ovarian transcriptome revealed that progesterone treatment of the ovaries altered the expression of 513 genes with 132 only expressed after $P_{4}$ treatment and 16 only expressed in control ovaries. The majority of genes were up-regulated greater than twofold over control, with a small subset of 16 genes down-regulated. Categories of genes affected by $\mathbf{P}_{4}$ are described including a group of extracellular signaling factors. The progesterone receptors expressed at the time of follicle assembly included the surface membrane progesterone receptors PGRMC1, PGRMC2, and RDA288. The nuclear genomic $P_{4}$ receptor was not expressed at appreciable levels. Progesterone increased the expression of several genes (TANK, NFK $B, B c I 2 I 1$, and $B C l 2 / 2)$ involved in a signaling pathway that promotes cell survival and inhibits apoptosis. Observations indicate that $P_{4}$ acts through the surface membrane progesterone receptors to regulate primordial follicle assembly, and that TNF $\alpha$ can override the inhibitory actions of $\mathbf{P}_{\mathbf{4}}$ on follicle assembly. A major mechanism involved in the actions of $\mathbf{P}_{\mathbf{4}}$ is an increase in cell survival genes and inhibition of the apoptosis pathway. Observations provide insight into the hormonal regulation of primordial follicle assembly and lead to novel approaches to potentially manipulate follicle assembly and reproductive capacity.
\end{abstract}

Reproduction (2006) 132 877-886

\section{Introduction}

Follicle assembly is the process by which 'nests' of oocytes break apart to form primordial follicles. Each primordial follicle is composed of a single oocyte arrested in the diplotene stage of the first meiotic division and surrounded by a single layer of squamous pre-granulosa cells. In rodents follicle assembly occurs in the first few days after birth (Peters \& Byskov 1975, Cran \& Moor 1980, Hirshfield 1991, Rajah \& Glaser 1992). In humans, follicle assembly begins during midgestation near week 18 and continues into the third trimester (Baker 1963, Fulton \& Martins da Silva 2005). The size (i.e. number) of the primordial follicle pool determines the reproductive lifespan of a female (Hirshfield 1994). Primordial follicles gradually leave the arrested pool by undergoing the primordial to primary follicle transition, after which they either undergo apoptotic atresia at any stage of follicle development or develop into a large antral follicle and ovulate. When the follicle pool is depleted, reproduction ceases and women enter menopause (Gosden \& Laing 1983, Richardson \& Senikas 1987, Faddy \& Gosden 1992, 1996, Faddy 2000). While the primordial follicle pool has been demonstrated to be finite (Hirshfield 1991), recent studies have suggested the possibility that new follicles with oocytes may form in adulthood (Johnson \& Canning 2004, Johnson \& Bagley 2005). The majority of literature suggests that a defined and finite pool of primordial follicles exists and a potential regenerative pool remains to be demonstrated.

Prior to the formation of primordial follicles, oogonia undergo mitotic proliferation and then enter the first meiotic division, becoming oocytes. These oocytes are 
present in clumps or 'nests' that are surrounded by somatic cells (Peters \& Byskov 1975, Cran \& Moor 1980, Hirshfield 1991, Rajah \& Glaser 1992, McNatty \& Fidler 2000). The pre-granulosa cells surround oocyte nests and in order to form a primordial follicle, an oocyte must become surrounded by an adequate number of the pregranulosa cells (Byskov \& Skakkebaek 1977, Juengel \& Sawyer 2002, Sawyer \& Smith 2002). The breakdown of oocyte nests for the assembly of primordial follicles is a process that involves the apoptotic death of oocytes (Tilly 1998, Morita \& Tilly 1999, Pepling \& Spradling 2001). The surviving oocytes become surrounded by pregranulosa cells to form primordial follicles. Studies have shown that ovaries and oocytes express tumor necrosis factor- $\alpha$ (TNF $\alpha$ ) at the time of follicular assembly in rodents, and TNF $\alpha$ treatment can increase oocyte apoptosis (Chen \& Marcinkiewicz 1993, Marcinkiewicz \& Krishna 1994, Kondo \& Maruo 1995, Marcinkiewicz \& Balchak 2002, Morrison \& Marcinkiewicz 2002). Observations suggest that TNF $\alpha$ is a stimulator of oocyte apoptosis that leads to oocyte nest breakdown and promotes assembly of primordial follicles.

Progesterone has been shown to have an inhibitory effect on primordial follicle assembly (Kezele \& Skinner 2003). The model proposed is that maternal/placentally derived progesterone inhibits follicle assembly in the rat until the time of parturition, after which levels of progesterone in the pups fall and follicle assembly occurs in a synchronous manner. In primates, follicle assembly occurs prior to birth in mid- to late gestation (Baker 1963). In a non-human primate, fetal progesterone levels decrease between mid-gestation and birth (Thau \& Lanman 1976), when follicle assembly occurs.

Interestingly, the inhibitory action of progesterone on follicle assembly is not blocked by RU486, which is an antagonist of the classical nuclear progesterone receptor (Kezele \& Skinner 2003). Since the action of progesterone on follicle assembly does not appear to be mediated by the nuclear progesterone receptor, the potential role of the cell surface membrane progesterone receptor is considered. Membrane progesterone receptors were first described in the spotted sea trout (Patino \& Thomas 1990) and then later in the pig (Falkenstein \& Meyer 1996). These membrane steroid receptors have been found to mediate rapid nongenomic responses to steroid hormones (Falkenstein \& Tillmann 2000, Sutter-Dub 2002). Several types of G-protein-coupled progesterone membrane receptors have been identified in the rat ovary. These include PRMC1, PMRa, PMRb, PMRg, and RDA288 (Peluso \& Pappalardo 1998, Peluso \& Fernandez 2001, Bramley 2003, Peluso \& Pappalardo 2004, Cai \& Stocco 2005).

The present study examines how TNF $\alpha$ and progesterone interact to regulate follicle assembly. Specifically, the ability of progesterone to inhibit follicle assembly in the absence or presence of TNF $\alpha$ was examined in vitro. In addition, the effect of an exogenous treatment with a non-metabolizable progesterone analog on follicle assembly in vivo was examined. A microarray analysis of gene expression in progesterone-treated and control ovaries at the time of follicle assembly was used to elucidate the potential mechanisms of action of progesterone on follicle assembly.

\section{Materials and Methods}

\section{Animal care and ovary dissection}

Sprague-Dawley rats were housed in a Washington State University IACUC-approved facility. Animals were kept in conditions of $14 \mathrm{~h}$ light: $10 \mathrm{~h}$ darkness and fed commercial rodent chow ad libitum. Female rat pups less than $8 \mathrm{~h}$ old were euthanized and ovaries were removed according to IACUC-approved animal use protocols. Alternatively, for in vivo studies, rat pups were left with their mothers and treated as described below.

\section{Organ culture protocols and treatments}

Newborn rat ovaries were dissected from freshly euthanized rat pups. Whole ovaries were cultured as previously described (Nilsson \& Parrott 2001) on floating filters $(0.4 \mu \mathrm{m}$ Millicell-CM, Millipore, Bedford, MD, USA) in $0.5 \mathrm{ml}$ Dulbecco's modified Eagle's medium (DMEM)-Ham's F-12 medium (1:1, vol/vol) containing $0.1 \%$ BSA (Sigma), 0.1\% Albumax (Gibco BRL, Gaithersburg, MD, USA), $27.5 \mu \mathrm{g} / \mathrm{ml}$ transferrin, $200 \mathrm{ng} / \mathrm{ml}$ insulin (human recombinant, Sigma), and $0.05 \mathrm{mg} / \mathrm{ml}$ L-ascorbic acid (Sigma) in a four-well culture plate (Nunc plate, Applied Scientific, South San Francisco, CA, USA). Ovaries were randomly assigned to treatment groups with two to three ovaries per floating filter in each well. Treatments during organ culture included recombinant rat tumor necrosis factor- $\alpha(\mathrm{TNF} \alpha)$ (R\&D Systems, Inc., Minneapolis, MN, USA) at $1 \mathrm{ng} / \mathrm{ml}$, which was a dose found to be effective in inducing the oocyte apoptosis that accompanies follicle assembly (Marcinkiewicz \& Balchak 2002). Some ovaries were treated with progesterone $\left(\mathrm{P}_{4}\right)$ (Sigma) at $10^{-6} \mathrm{M}$. The medium was supplemented with penicillin and streptomycin to prevent bacterial contamination. After culture, ovaries were fixed, sectioned at $3 \mu \mathrm{m}$, and stained with hematoxylin/eosin for use in morphological analysis. Alternatively, if mRNA levels were to be measured from cultured ovaries, after culture ovaries from one treatment group were pooled and homogenized in $1 \mathrm{ml}$ Trizol (Gibco BRL, Rockville, MD, USA) and stored at $-20{ }^{\circ} \mathrm{C}$ until RNA isolation.

\section{Neonatal rat in vivo treatment protocols}

Newborn rats less than 8-h-old were kept with their mothers and treated by s.c. injection with $20 \mu$ l of $10^{-4} \mathrm{M}$ 
19-nor-progesterone, a non-metabolizable progesterone analog (Sigma), or with sesame oil vehicle alone. This resulted in a calculated nor-progesterone concentration in the rat pup of $1-2 \times 10^{-6} \mathrm{M}$, depending on the size of the rat pup. The nor-progesterone solution was prepared by dissolving nor-progesterone in ethanol to make a $10^{-2} \mathrm{M}$ stock solution, then diluting the same with sesame oil to make a $10^{-4} \mathrm{M}$ injection solution. Rats were treated daily for either 2 or 4 days, after which ovaries were fixed for 1-2 $\mathrm{h}$ in Bouin's solution and paraffin-embedded prior to sectioning and hematoxylin/eosin staining.

\section{Morphological analysis}

The number of oocytes at each developmental stage was counted in two, $3 \mu \mathrm{m}$ sections and averaged from the largest cross-sections through the center of the ovary. The oocyte nucleus had to be visible in order to be counted. Normally, 100-200 oocytes were present in a cross-section. Oocytes were classified as either being not yet assembled into follicles (i.e. the oocyte was part of an unassembled oocyte nest), as primordial (stage 0) or as one of the developing pre-antral stages (stages 1-4) as described previously (Parrott \& Skinner 1999, Kezele \& Skinner 2003). Briefly, unassembled oocytes are clumped together with other oocytes without any intervening cells separating them. Primordial follicles consist of an oocyte partially or completely encapsulated by squamous pre-granulosa cells. Developing (stages 1-4) follicles contain successively more cuboidal granulosa cells in layers around the oocyte (Parrott \& Skinner 1999, Nilsson \& Parrott 2001).

\section{$R N A$ isolation and $C D N A$ production protocol}

Ovaries from the same culture well were pooled to make each RNA sample. RNA was extracted using the Trizol reagent (Sigma). RNA samples were DNase treated using the TURBO-DNA-free kit (Ambion, Austin, TX, USA). Using a standard oligo-dT reverse transcriptase (RT) protocol in a reaction volume of $25 \mu \mathrm{l}, 2 \mu \mathrm{g}$ total RNA from each sample was reverse transcribed into cDNA. Alternatively, RNA was reverse transcribed using the Invitrogen SuperScript III First-strand Synthesis System for RT-PCR kit (Invitrogen). cDNA was stored at $-20{ }^{\circ} \mathrm{C}$ until use.

\section{Microarray and bioinformatics}

Gene expression was determined with an Affymetrix (Affymetrix, Santa Clara, CA, USA) rat RAE230 2.0 expression array. Two pooled independent RNA samples were analyzed for each treatment group (control or $\mathrm{P}_{4}$-treated ovaries cultured for 2 days). Genomics Core in the Center for Reproductive Biology performed the analysis as previously described (Shima \& McLean
2004). Briefly, RNA was reverse transcribed into cDNA and this was transcribed into biotin-labeled RNA, which was hybridized to the RAE230 2.0 arrays. Each gene set is composed of 11 pairs of 24-mer oligonucleotides, with one strand complimentary and specific for the gene and one strand having single point mutations for use as a negative control. Biotinylated RNA was then visualized by labeling with phycoerythrin-coupled avidin. The microarray was scanned on a Hewlett-Packard Gene Array Scanner (Hewlett-Packard). The microarray image data were converted to numerical data with GeneChip Operating Software using a scaling factor of 125, then imported into the GeneSpring program (Agilent Technologies, Palo Alto, CA, USA) where raw data were filtered for flags (present/absent calls), expression level, fold change, and confidence ( $t$-test, $P$ value) with no multiple testing correction.

\section{Semi-quantiative PCR}

RNA from day 0 ovaries that were cultured for 2 days with or without progesterone was isolated as described above. Replicate samples prepared from different ovary preparations were made for control and progesteronetreated groups. Total RNA, $2 \mu \mathrm{g}$ from each sample was reverse transcribed to CDNA. PCR analysis to test for the presence of progesterone membrane surface receptors used cDNA diluted in the ratio of 1:5 prior to use as template. Primer sequences are as follows: PGRMC1-1-F $=$ CTGCTTCAGTCACTCTTCCGAG; PGRMC1-1-R = TGGGACTCTCAGTTCACCTTCA; PGRMC2-2-F=ATTTGAACGCAGTGCAGATG; and PGRMC2-2-R=TGATCCTTGGTGTCCTCCTC. The constitutively expressed ribosomal subunit gene L19 was used as an internal control. Primer sequences are $\mathrm{L} 19 \mathrm{~F}=\mathrm{CTGAAGGT}$ CAAAGGGAATGTG and L19R=GGACAGAGTCTTGATGATCTC. Amplification was performed using the following conditions: $1.0 \mu \mathrm{M}$ each primer, $50 \mu \mathrm{M}$ dNTPs, $1.5 \mathrm{mM} \mathrm{MgCl} 2,0.004$ Units Bioline MangoTAQ polymerase (Bioline, Inc., Springfield, NJ, USA) and $2 \mu \mathrm{l}$ diluted cDNA in $25 \mu \mathrm{l} 1 \times$ Bioline PCR buffer. Each PCR amplification consisted of an initial denaturing reaction $\left(2 \mathrm{~min}, 95^{\circ} \mathrm{C}\right)$; 30 cycles of denaturation (30 s, $\left.95^{\circ} \mathrm{C}\right)$, annealing $\left(90 \mathrm{~s}, 53{ }^{\circ} \mathrm{C}\right)$, and elongation $(60 \mathrm{~s}$, $\left.72{ }^{\circ} \mathrm{C}\right)$; and a final elongation reaction $\left(10 \mathrm{~min}, 72{ }^{\circ} \mathrm{C}\right)$.

\section{Statistical analysis}

Comparisons between two groups were performed using Student's $t$-test. Multiple comparison tests were performed using Tukey's multiple comparison test after a significant difference had been found with an ANOVA. Groups were considered significantly different with $P \leq 0.05$. All statistics were calculated with the help of GraphPad Prism version 3.0a for Macintosh, GraphPad Software, San Diego, CA, USA. 


\section{Results}

Organ culture experiments were performed in order to determine if progesterone and TNF $\alpha$ interact to regulate primordial follicle assembly. Ovaries from newborn 0-day-old rat pups were placed into a floating filter organ culture system and treated with either progesterone $\left(\mathrm{P}_{4}\right), T N F \alpha, T N F \alpha$, and $\mathrm{P}_{4}$, or left untreated as controls. After 2 days of culture, the ovaries were fixed, sectioned, stained and the proportion of oocytes assembled into follicles was determined relative to the proportion still present in oocyte nests. Treatment of ovaries with TNF $\alpha$ did not result in a change in the proportion of assembled follicles relative to controls. However, treatment with $\mathrm{P}_{4}$ significantly reduced the proportion of assembled primordial follicles (Fig. 1). Interestingly, ovaries treated with both TNF $\alpha$ and $\mathrm{P}_{4}$ had a proportion of assembled follicles that was the same as those of control or TNF $\alpha$-treated ovaries (Fig. 1). This indicates that TNF $\alpha$ was able to reverse the inhibition of follicle assembly that $\mathrm{P}_{4}$ treatment induced.

Previously, progesterone was found to inhibit primordial follicle assembly in vivo (Kezele \& Skinner 2003). These observations are extended here to determine the effects of a non-metabolizable progesterone analog. The effects of $\mathrm{P}_{4}$ on follicle assembly were tested using an in vivo system in which newborn rat pups were injected daily with 19 norprogesterone and left with their mothers for either 2 or 4 days. Control pups were injected daily with vehicle alone. The ovaries were then fixed, sectioned, stained and the proportion of oocytes assembled into follicles was determined. After 2 days of treatment, there was a

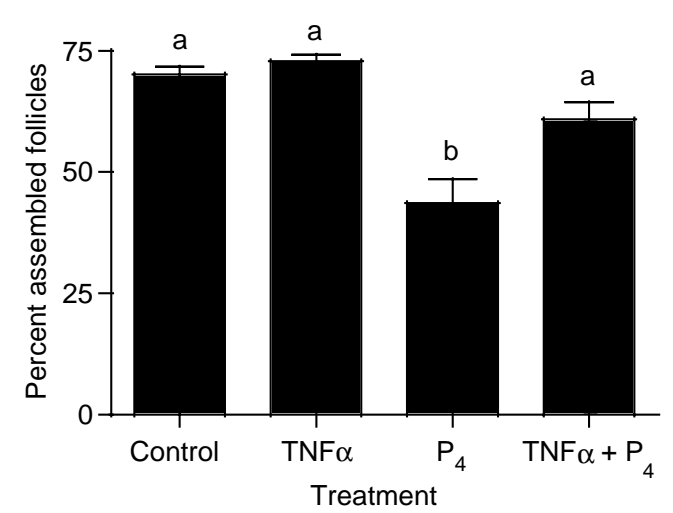

Figure 1 Effect of TNF $\alpha$ and $\mathrm{P}_{4}$ treatment on follicle assembly in cultured ovaries. Ovaries from 0-day-old rats were placed into culture for 2 days. Cultured ovaries were treated with TNF $\alpha, \mathrm{P}_{4}$, both TNF $\alpha$ and $\mathrm{P}_{4}$, or were left untreated as controls. After culture ovaries were fixed, stained, and subjected to morphological analysis. The oocytes in each ovary cross-section were counted and categorized as being either unassembled or primordial. Data are presented as the number of oocytes (mean \pm s.E.M..) per category divided by the control mean with data pooled from eight separate experiments $(n=5-23 /$ treatment group). One-way ANOVA showed a significant $(P<0.0001)$ effect of treatment. Bars with different superscript letters indicates that treatment groups are significantly $(P<0.01)$ different by post hoc Tukey's test. significant increase in the proportion of oocytes remaining unassembled in 19 nor-progesterone-treated rat pups compared with controls (Fig. 2A). After 4 days of treatment, the proportion of oocytes remaining unassembled was relatively small compared with that seen at 2 days (Fig. 2B). However, after 4 days there was still an increase in the proportion of oocytes remaining unassembled primordial follicles in 19 nor-progesterone-treated rat pups compared with the controls (Fig. 2B). Therefore, the progesterone analog delayed the assembly of primordial follicles, but could not block primordial follicle assembly. Analysis of total follicle numbers demonstrated no change in the total number of follicles after nor-progesterone treatment (data not shown). Therefore, the primordial follicle pool size was not affected.

In order to gain an understanding of the suite of genes affected by progesterone at the time of follicle assembly, a gene expression microarray analysis was performed using RNA collected from cultured $\mathrm{P}_{4}$-treated and control ovaries. Day 0 ovaries were cultured for 2 days with or without $\mathrm{P}_{4}$ and RNA samples were collected from
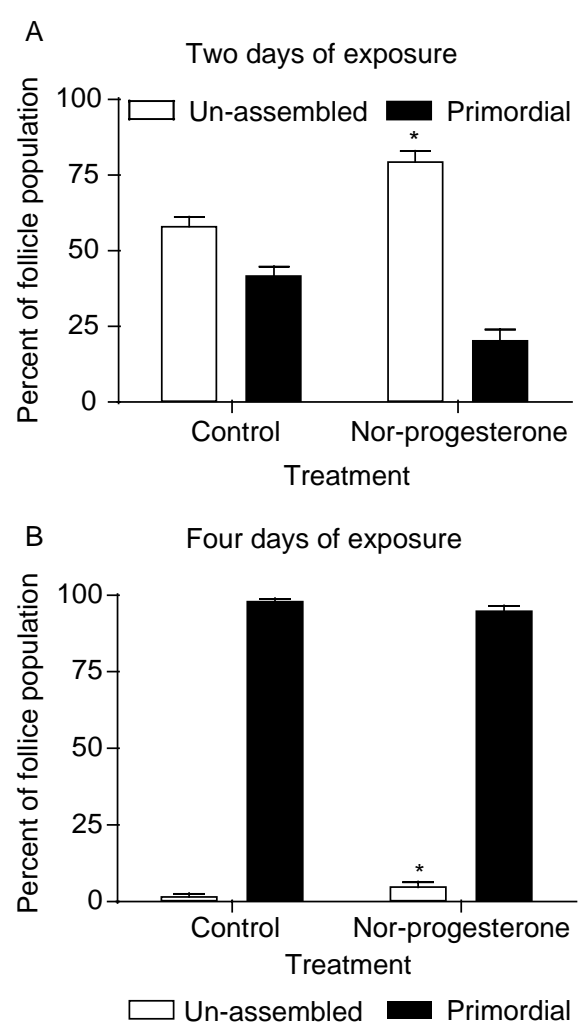

Figure 2 Effect of nor-progesterone treatment on follicle assembly in vivo. The 0-day-old rats were treated with nor-progesterone or vehicle for 2 days (A) or 4 days (B). After culture ovaries were fixed, stained, and subjected to morphological analysis. The oocytes in each ovary cross-section were counted and categorized as being either unassemble or primordial. Data are presented as the mean \pm s.E.M. percentage follicles per category with data pooled from two separate experiments ( $n=11-16$ animals per treatment group). *Significant $(P<0.05)$ difference between control and nor-progesterone treated groups by Student's $t$-test. 
two different sets of organ cultures. The RNA samples were analyzed using Affymetrix RAE 2302.0 expression arrays. Analysis of the microarray detected 513 gene transcripts that showed a twofold change between control and $\mathrm{P}_{4^{-}}$ treated ovaries and had a raw expression value over 100. A Venn diagram illustrates how many of these 513 transcripts were expressed in the control versus progesterone-treated ovaries, and the number of genes unique to each (Fig. 3A). A dendogram illustrates the overall degree of change (Fig. 3B). Only 16 transcripts were down-regulated in $\mathrm{P}_{4^{-}}$ treated ovaries and 493 were up-regulated. The list of down-regulated transcripts is presented in Table 1. The 513 regulated transcripts were grouped into functional categories (e.g. cell cycle, transcription, and apoptosis) using Genespring software (Fig. 4). The major functional categories influenced were signaling and transcription, not considering expressed sequence tags (EST) sequences. An example of a category of increased genes is the extracellular-secreted regulatory factors shown in Table 2. The complete raw dataset for this expression array analysis may be accessed online at www.skinner. wsu.edu.

The expression array analysis revealed that several progesterone membrane surface receptors were expressed in these ovaries at the time of follicle assembly,

A

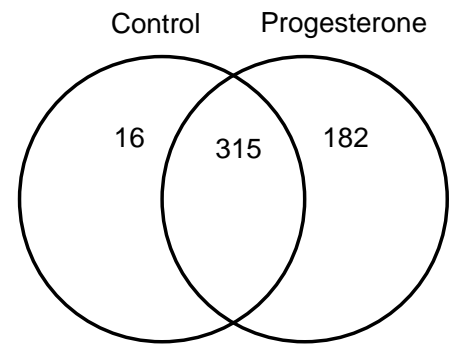

B

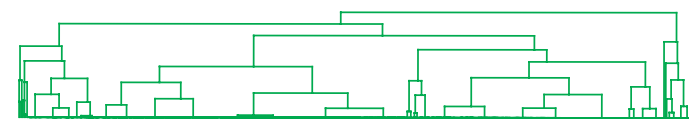

Control

\section{(1)}

.

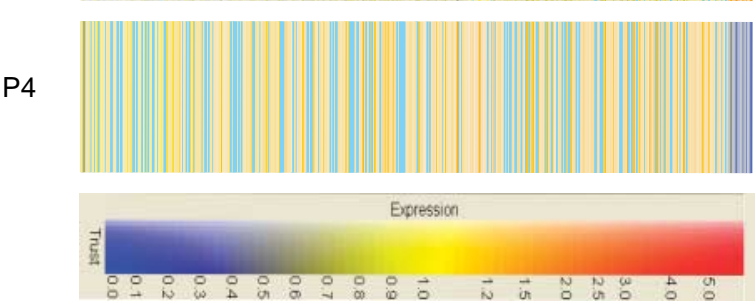

Figure 3 Microarray analysis results for the 513 genes that show a twofold expression change between $\mathrm{P}_{4}$-treated and control ovaries, and have a raw expression value over 100. (A) Venn diagram illustrating the number of genes unique to each treatment group. (B) Dendogram illustrating the degree of change of expression for each. Blue, decreased expression levels. Red, increased expression levels. while transcripts for the traditional nuclear $\mathrm{P}_{4}$ receptor were not expressed at appreciable levels (Table 3). The genes for progesterone receptor membrane component 1 (PGRMC1), progesterone receptor membrane component 2 (PGRMC2) and RDA288 had raw expression level values $>100$. Conversely, transcripts of genes coding for the known progesterone membrane surface receptors progestin membrane receptor beta $(P M R-\beta)$ and progestin membrane receptor gamma $(P M R-\gamma)$ were not expressed in these ovaries at the time of follicle assembly. In order to confirm these and in general the microarray results RNA samples from cultured 0-day-old ovaries were subjected to semi-quantitative PCR analysis with primers designed to detect the presence of the progesterone membrane surface receptors PGRMC1 and PGRMC2. The results of this PCR experiment show that PGRMC1 and PGRMC2 are present in ovaries at the time of follicle assembly as assayed in ovaries from 3-day-old rat pups (in vitro) and from day 0 ovaries cultured 3 days (in vitro) (Fig. 5A). A constitutively expressed gene, ribosomal probe L19, was used as a control. The expression of PGMRC1 increased approximately 1.5 -fold after nor-progesterone treatment of day 0 rats in vivo (Fig. 5B), but not PGRMC2. Similar results were observed in vitro after progesterone treatment with the microarray analysis of PGMRC1 showing a 1.5-fold increase (Table 3). The PGMRC2 did not change using either the microarray (Table 3) or semi-quantitative PCR (Fig. 5) procedures. Therefore, the membrane progesterone receptors are expressed during primordial follicle assembly, but not the nuclear receptor.

Further analysis of the expression microarray results revealed that several genes known to be involved in apoptosis/cell survival signaling pathways had transcripts that were differentially regulated between $\mathrm{P}_{4}$-treated and control-cultured ovaries (Fig. 6). Progesterone increased expression levels of TANK (TRAF family member-associ-

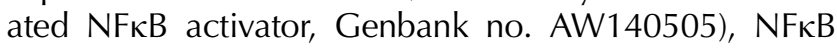
(Nuclear factor kappa B p105 subunit, Genbank no. AA858801), Bcl2I1 (Bcl2-like 1, Genbank no. U72350), and $\mathrm{Bcl} 2 \mathrm{l} 2$ (Bcl2-like 2, Genbank no. AW527957). Progesterone also increased expression of $\mathrm{I} \mathrm{B} \alpha(\mathrm{NF}-\kappa \mathrm{B}$ inhibitor- $\alpha$, Genbank no. AW672589). These genes would be expected to promote cell survival (Fig. 6). The progesterone actions increased the expression of genes involved in cell survival, suppressing the TNF $\alpha$ pathway and apoptosis. In addition, as shown in Table 2, progesterone increased expression of several growth factorsignaling pathways, such as TGF $\beta$ that promote cell survival (Fig. 7). Both TGF $\beta$ and bone morphogenic protein $(B M P)$ genes were increased and correlated with an increase in the TGF $\beta$ pathway. A number of the known growth factors include Tgfb3, Igfbp5, Ledgf, and Ctgf (Table 2). Most are homologs or predicted regulatory growth factors. All these factors are candidates potentially involved in the control of primordial follicle assembly that require further investigation. 
Table 1 Genes down-regulated in progesterone treated ovaries.

\begin{tabular}{|c|c|c|c|}
\hline \multirow[b]{2}{*}{ Genbank no. } & \multicolumn{2}{|c|}{ Raw signal values (mean) } & \multirow[b]{2}{*}{ Gene description } \\
\hline & Control & $\mathrm{P}_{4}$ & \\
\hline BE096523 & 692 & 90 & Interferon-stimulated protein (LOC298693), mRNA (G1p2_predicted) \\
\hline NM_017028 & 182 & 30 & Mx3 protein (AA 1 - 659); myxovirus (influenza virus) resistance $3(M \times 2)$ \\
\hline NM_053687 & 190 & 38 & Schlafen 4 (Slfn4) \\
\hline $\mathrm{Al} 233121$ & 415 & 83 & Chromosome 20, major histocompatibility complex (RT1-T24-1) \\
\hline X52711 & 224 & 46 & Myxovirus (influenza virus) resistance $(\mathrm{M} \times 1)$ \\
\hline BF411036 & 450 & 96 & Irf7_predicted interferon regulatory factor 7 \\
\hline AJ243974 & 207 & 65 & $\mathrm{MHC}$ class Ib (RT1.S3) \\
\hline AA819034 & 1595 & 544 & Hypothetical LOC299269 mRNA.putative ISG12(b) protein \\
\hline AA819788 & 303 & 117 & Rattus norvegicus similar to 5830458K16Rik protein (LOC360733), mRNA \\
\hline Al639117 & 179 & 70 & Complement component 2 (C2) \\
\hline AA924350 & 151 & 63 & Rattus norvegicus transcribed sequences \\
\hline U22520 & 111 & 49 & Chemokine (C-X-C motif) ligand 10 (Cxcl10) \\
\hline Al409634 & 163 & 73 & Hypothetical gene supported by NM_138881 (LOC360410), mRNA (Best5) \\
\hline AA957923 & 141 & 66 & Mast cell protease 2 (Mcpt2) \\
\hline NM_130743 & 2360 & 1142 & Interferon, $\alpha$-inducible protein 27 -like [lfi27I] \\
\hline BI295179 & 209 & 104 & Rattus norvegicus transcribed sequence \\
\hline
\end{tabular}

\section{Discussion}

The present study examined the effects of TNF $\alpha$ and $\mathrm{P}_{4}$ on the assembly of primordial follicles, and also the mechanisms by which $\mathrm{P}_{4}$ may exert its effects on follicle assembly. Previously, $\mathrm{P}_{4}$ treatment of cultured ovaries has been shown to decrease primordial follicle assembly (Kezele \& Skinner 2003). In the present study, both in vitro and in vivo progesterone treatment experiments confirm that progesterone decreases follicle assembly. When neonatal rat pups were treated for 2 days with non-metabolizable nor-progesterone, the ovaries showed a $20 \%$ increase in unassembled follicles compared with the controls. This level of inhibition was slightly greater than progesterone alone (Kezele \& Skinner 2003), but not dramatically different. At this developmental time, follicle assembly is about half completed. After 4 days in vivo, most oocytes have assembled into follicles whether the pups received norprogesterone treatment or not. However, nor-progesterone-treated 4-day old pups had some oocytes (about $8 \%$ ) unassembled, while unassembled oocytes were virtually undetectable in controls. These data suggest that $\mathrm{P}_{4}$ regulates follicle assembly, but that $\mathrm{P}_{4}$ is not the only factor that drives or inhibits follicle assembly, since follicle assembly still occurs in the presence of increased $\mathrm{P}_{4}$ levels. Previous literature suggests that estrogen is another steroid hormone important for follicle assembly in the mouse (Jefferson \& Newbold 2006, Pepe \& Billiar 2006), rat (Kezele \& Skinner 2003), and baboon (Pepe \& Billiar 2006), but estrogen likely plays a greater role in arresting the primordial follicle in the primordial stage and not allowing the primordial to primary follicle transition (Kezele \& Skinner 2003).

TNF $\alpha$ has been implicated as a growth factor that promotes the oocyte apoptosis thought to be necessary for follicle assembly to occur (Chen \& Marcinkiewicz 1993,
Marcinkiewicz \& Krishna 1994, Kondo \& Maruo 1995, Morrison \& Marcinkiewicz 2002, Marcinkiewicz \& Balchak 2002). In the present study, TNF $\alpha$ treatment of cultured ovaries does not change the rate or percentage of assembled follicles compared with controls. In earlier work by Marcinkiewicz \& Balchak (2002), treatment of

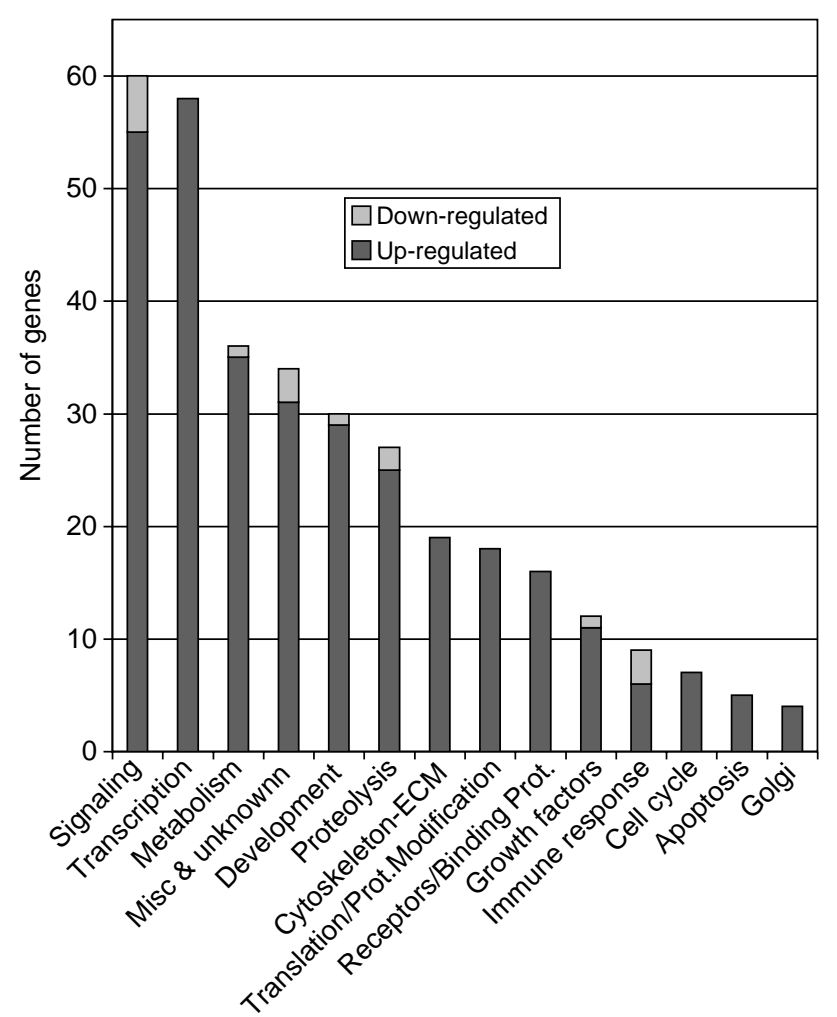

Figure 4 Expression microarray analysis results for gene transcripts that show a twofold expression change between $\mathrm{P}_{4}$-treated and control ovaries, and have an expression value over 100 . The transcripts are divided into functional categories, with each transcript only present in one category. ESTs (165 transcripts) are not shown. Extracellular matrix (ECM). 
Table 2 Selected extracellular signaling factors and receptors.

\begin{tabular}{|c|c|c|c|c|c|}
\hline \multirow[b]{2}{*}{ Common } & \multirow[b]{2}{*}{ Genbank no. } & \multicolumn{3}{|c|}{ Raw signal values (mean) } & \multirow[b]{2}{*}{ Description } \\
\hline & & Control & $\mathrm{P}_{4}$ & Fold change & \\
\hline Cxcl10 & U22520 & 111 & 49 & 0.44 & Chemokine (C-X-C motif) ligand 10 \\
\hline Ifi27| & NM_130743 & 2360 & 1142 & 0.48 & Interfon, $\alpha$-inducible protein 27 -like \\
\hline $\begin{array}{l}\text { B35272 osteoinductive } \\
\text { factor }\end{array}$ & BG664221 & 212.9 & 430 & 2.03 & $\begin{array}{l}\text { Rattus norvegicus transcribed sequence with moderate } \\
\text { similarity to protein pir:B35272 (Homo Sapien) }\end{array}$ \\
\hline Creg_predicted & BE099979 & 78 & 163 & 2.09 & $\begin{array}{l}\text { Rattus norvegicus transcribed sequence with moderated } \\
\text { similarity to preotein ref:NP_003842.1 ( H. Sapien) }\end{array}$ \\
\hline Tgfb3 & NM_013174 & 97 & 215 & 2.22 & Transforming growth factor, $\bar{\beta} 3$ \\
\hline Stc1 & BF5 $5 \overline{2} 244$ & 193 & 434 & 2.25 & Stanniocalcin 1 \\
\hline Igfbp5 & BF399783 & 155 & 393 & 2.54 & Insulin-like gowth factor-binding protein 5 \\
\hline Procr_predicted & Al37406 & 453 & 1176 & 2.60 & $\begin{array}{l}\text { Rattus norvegicus similar to endothelial cell protein C/APC } \\
\text { receptor (LOC362248), mRNA }\end{array}$ \\
\hline Igfbp5 & BF399783 & 56 & 186 & 3.32 & Insulin-like growth factor-binding protein 5 \\
\hline Ctgf & NM_022266 & 66 & 243 & 3.68 & Connective tissue growth factor \\
\hline Cxcl14 & BG380414 & 22 & 118 & 5.36 & $\begin{array}{l}\text { Rattus norvegicus transcribed sequences. Chemokine (C-X-C } \\
\text { motif) ligand } 14 \text { [Mus musculus] }\end{array}$ \\
\hline Ledgf & BF397366 & 141 & 259 & 1.77 & Lens epithelium-derived growth factor \\
\hline Tob1 & NM_133317 & 163 & 337 & 2.07 & Transducer of ERBB2, 1 \\
\hline C1qg_predicted & A411618 & 107 & 222 & 2.07 & $\begin{array}{l}\text { Rattus norvegicus transcribed sequence with moderate } \\
\text { similarity to protein pit:C1HUQC }(H \text {. sapien })\end{array}$ \\
\hline
\end{tabular}

cultured rat ovaries with TNF $\alpha$ resulted in a reduction in both the number of unassembled oocytes and the number of oocytes assembled into primordial follicles in the ovary. Since both the number of assembled and unassembled oocytes decreased in treated ovaries, the percentage of assembled follicles was similar in treated compared with the control ovaries. In the present study, the percentage of assembled follicles was similar in control and TNF $\alpha$ treated ovaries. TNF $\alpha$-treated ovaries had on average fewer unassembled oocytes in ovary cross-sections, but this decrease was not statistically significant due to the variation between ovaries. The total number of follicles per cross-section in TNF $\alpha$-treated ovaries was $108 \pm 11$ compared with $116 \pm 8$ in control ovaries.

In order to determine how $\mathrm{P}_{4}$ and TNF $\alpha$ might interact to regulate follicle assembly, cultured ovaries were treated with $\mathrm{P}_{4}, \mathrm{TNF} \alpha, \mathrm{TNF} \alpha$, and $\mathrm{P}_{4}$, or were left untreated as controls. Observations demonstrated that when ovaries were treated with both TNF $\alpha$ and $\mathrm{P}_{4}, \mathrm{TNF} \alpha$

Table 3 Progesterone receptor family.

\begin{tabular}{|c|c|c|c|c|}
\hline \multirow[b]{2}{*}{ Common } & \multirow[b]{2}{*}{ Genbank no. } & \multicolumn{2}{|c|}{ Raw signal values } & \multirow[b]{2}{*}{ Description } \\
\hline & & Control & $\mathrm{P}_{4}$ & \\
\hline Pgr & NM_022847 & 22 & 16 & $\begin{array}{l}\text { Nuclear progesterone } \\
\text { receptor }\end{array}$ \\
\hline Pgrmc1 & NM_021766 & 813 & 1188 & $\begin{array}{l}\text { Progesterone receptor } \\
\text { membrane component } 1\end{array}$ \\
\hline Pgrmc2 & BF283382 & 237 & 346 & $\begin{array}{l}\text { Progesterone receptor } \\
\text { membrane component } 2\end{array}$ \\
\hline Rda288 & AF388527 & 2312 & 3221 & $\begin{array}{l}\text { Hypothetical RNA-bind- } \\
\text { ing protein RDA288 }\end{array}$ \\
\hline PMR- $\beta$ & BF405077 & 6 & 6 & $\begin{array}{l}\text { EST, Progesterone } \\
\text { Membrane Receptor- } \beta\end{array}$ \\
\hline PMR- $\gamma$ & BM384409 & 3 & 2 & $\begin{array}{l}\text { EST, Progesterone } \\
\text { Membrane Receptor- } \gamma\end{array}$ \\
\hline
\end{tabular}

Signals $<50$ are considered non-detectable levels of expression.

\section{A}
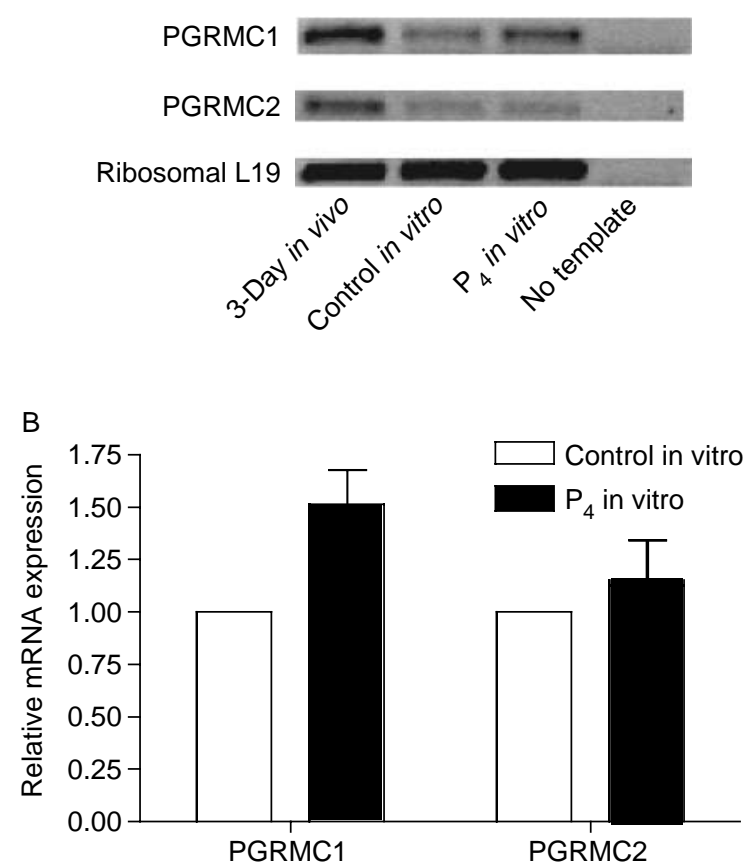

Figure 5 Semi-quantitative PCR for progesterone membrane receptors PGRMC1 and PGRMC2. (A) Representative gel showing PCR product bands for PGRMC1 and PGRMC2 from ovaries from 3-day old rat pups (in vivo), from day 0 ovaries cultured for 3 days and treated with vehicle (control in vitro) or nor-progesterone (P4 in vitro), and from a negative control PCR reaction receiving no cDNA template. (B) Densitometric analysis of PCR product bands from gels of two separate experiments comparing progesterone membrane receptor expression between ovaries from nor-progesterone treated versus control ovaries in vitro. Data are expressed as sample band raw volume scores divided by the corresponding L19 volume score, and then normalized so that control values are equal to one. 


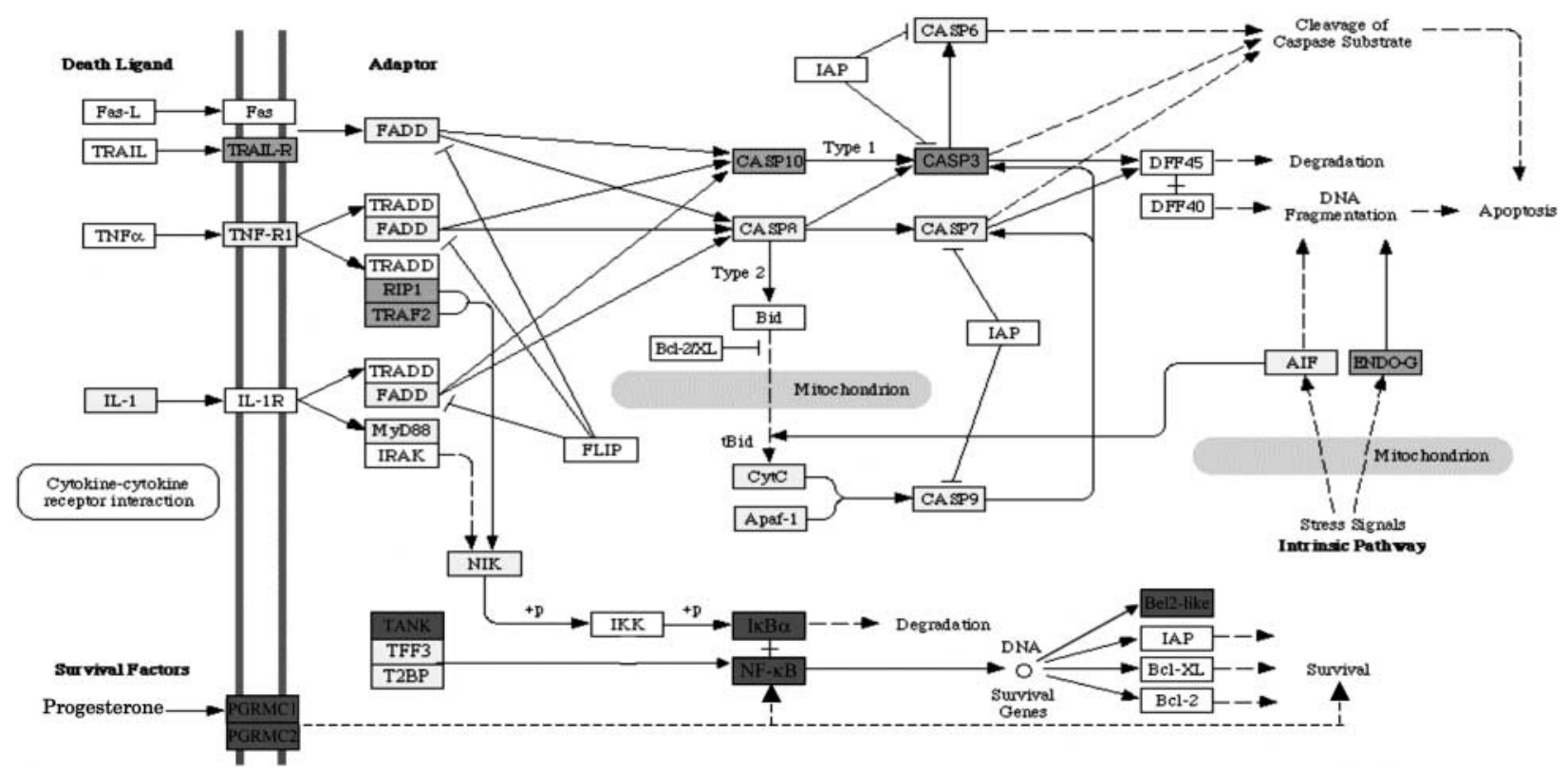

Figure 6 Illustration of signaling pathways involved in apoptosis/cell survival proposed to be involved in regulating follicle assembly using microarray data. Genes that are up-regulated by $\mathrm{P}_{4}$ treatment are shown in green. Genes that are not changing in expression level are shown in yellow. Genes that are not expressed at levels above a raw score of 75 are shown in white. Genes that are not represented on the Affymetrix RAE 230 2.0 chip are shown in grey. Pathways adapted from Kyoto encyclopedia of genes and genomes (KEGG) pathways as accessed through GeneSpring GX 7.3 Expression analysis (Agilent Technologies, Palo Alto, CA, USA).

was able to reverse the inhibition of follicle assembly induced by $\mathrm{P}_{4}$ treatment. This indicates that TNF $\alpha$ signaling pathways are intact and functional in the neonatal ovary, and the stimulatory actions TNF $\alpha$ has on follicle assembly may act downstream of the inhibitory actions $\mathrm{P}_{4}$ has on follicle assembly. Alternatively, TNF $\alpha$ and $\mathrm{P}_{4}$ may act in separate and parallel pathways to regulate follicle assembly. The actions of TNF $\alpha$ appear to be dominant at the dose and culture conditions of these experiments.

RNA samples from $\mathrm{P}_{4}$-treated and control ovaries were subjected to a microarray analysis in order to gain an understanding of those genes whose expression is affected by progesterone at the time of follicle assembly. Interestingly, out of the 513 genes differentially expressed in $\mathrm{P}_{4}$-treated ovaries, only 16 were downregulated. These 16 genes included 7 that could be considered to be involved in immune function, including a chemokine, major histocompatibility complex (MHC) class proteins, myxovirus resistance proteins, a complement cascade component, and a predicted interferon regulatory factor. The idea that components of the immune system may be involved in processes occurring during follicle assembly merits further investigation.

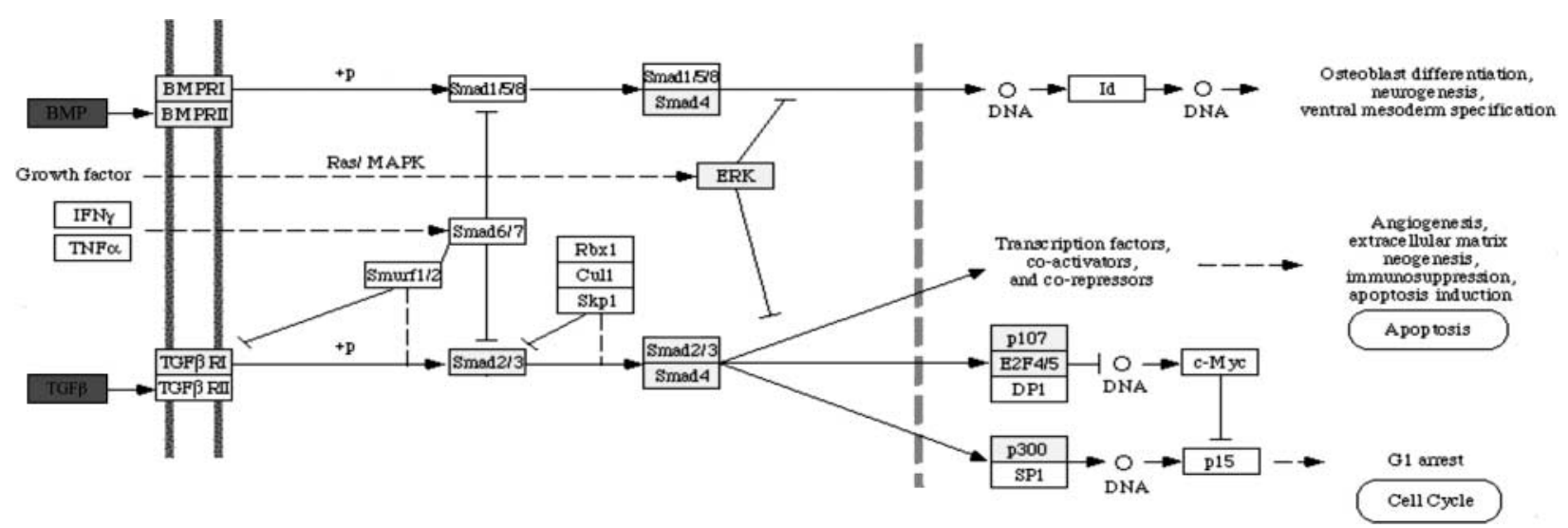

Figure 7 Illustration of TGF $\beta$ family signaling pathways proposed to be involved in regulating follicle assembly using microarray data. Genes that are up-regulated by $\mathrm{P}_{4}$ treatment are shown in green. Genes that are not changing in expression level are shown in yellow. Genes that are not expressed at levels above a raw score of 75 are shown in white. Genes that are not represented on the Affymetrix RAE 2302.0 chip are shown in grey. Pathways adapted from KEGG pathways as accessed through GeneSpring GX 7.3 Expression analysis (Agilent Technologies, Palo Alto, CA, USA). 
Examination of microarray results revealed that three transcripts for known progesterone membrane surface receptors are expressed in ovaries at the time of follicle assembly. The transcript for the classic nuclear progesterone receptor was not expressed at detectable levels. The actions of $\mathrm{P}_{4}$ on follicle assembly appear to be mediated through the surface membrane progesterone receptor. This is consistent with the results of previous work in which the ability of $\mathrm{P}_{4}$ to inhibit follicle assembly was not affected by the nuclear progesterone receptor antagonist RU486 (Kezele \& Skinner 2003). The expression microarray results of the present study are further supported by semi-quantitative PCR results showing the presence of the surface membrane progesterone receptors PGRMC1 and PGRMC2, both in vitro and in vivo (Fig. 5). Results of the semiquantitative PCR demonstrated that PGRMC1, but not PGRMC2, increased 1.5-fold, but was not statistically significant. This increase was similar to the 1.5 -fold increase in PGRMC1 expression observed in vitro after progesterone treatment by microarray analysis. This confirmed the regulation of PGRMC1 expression by progesterone and helped validate the microarray observations. Previous studies have shown physiologic responses to $\mathrm{P}_{4}$ that are characteristic of surface membrane progesterone receptor activation in the ovaries or ovarian cells of rat, human, and pig (Bramley 2003), and have documented the expression of several surface membrane progesterone receptors in rat corpora leutea (Bramley 2003, Cai \& Stocco 2005). Taken together, these results indicate that the actions of $\mathrm{P}_{4}$ in regulating follicle assembly appear to be mediated through surface membrane progesterone receptors.

One possible mechanism by which $\mathrm{P}_{4}$ could inhibit follicle assembly would be if $\mathrm{P}_{4}$ down-regulated TNF $\alpha$ expression. Examination of expression microarray results was unable to confirm this hypothesis. TNF $\alpha$ mRNA levels in whole ovary samples were too low to detect differences in expression between control and $\mathrm{P}_{4}$-treated ovaries. At this developmental stage, TNF $\alpha$ expression has been demonstrated to be limited to oocytes in ovaries (Marcinkiewicz \& Krishna 1994, Marcinkiewicz \& Balchak 2002). It is possible that TNF $\alpha$ mRNA from oocytes has been so diluted by somatic cell RNA as to interfere with TNF $\alpha$ microarray detection.

Examination of expression microarray results revealed that several components of apoptosis/cell survival signaling pathways were up-regulated in $\mathrm{P}_{4}$-treated ovaries (Fig. 6). $\mathrm{P}_{4}$ increased expression of TANK, $\mathrm{NF \kappa B}, \mathrm{Bcl} 2 \mathrm{l} 1$, and $\mathrm{Bcl} 2 \mathrm{l} 2$, all of which promote cell survival rather than apoptosis. Since apoptosis is an important part of follicle assembly, these actions of $\mathrm{P}_{4}$ are consistent with inhibiting follicle assembly. In addition, increased expression of a number of growth factors, such as TGF $\beta$, BMP, and IGF1 promote cell survival (Fig. 7). Observations suggest the changes in gene expression induced by $\mathrm{P}_{4}$ seem to tip the balance of the signaling pathways toward cell survival, which would inhibit follicle assembly.

The present study demonstrates that $\mathrm{P}_{4}$ and TNF $\alpha$ can interact in regulating primordial follicle assembly and that TNF $\alpha$ can override the inhibitory actions $\mathrm{P}_{4}$ has on follicle assembly. $\mathrm{P}_{4}$ appears to act through signaling via surface membrane progesterone receptors rather than through nuclear genomic receptors. A mechanism involved in the ability of $\mathrm{P}_{4}$ to inhibit follicle assembly is up-regulation of several components of a signaling cascade that promotes cell survival rather than apoptosis. Since apoptosis of some oocytes is an important part of the follicle assembly process, the result is that follicle assembly is inhibited.

Primordial follicle assembly is the process that forms the pool of primordial follicles. The size of this arrested pool of follicles is an important determinant of reproductive lifespan in mammalian females. Observations provide a number of candidate regulatory factors and genes potentially involved in the control of primordial follicle assembly. The results of the present study provide insight into the regulation of this vital process, and may lead to ways of manipulating follicle assembly so as to improve reproductive capacity.

\section{Acknowledgements}

We acknowledge the expert technical assistance of Ms Natalie Rodgers and Ms Gretchen Dole. We thank Ms Jill Griffin and Ms Rochelle Pedersen for the assistance in preparation of the manuscript. This research was supported by a grant from $\mathrm{NIH}, \mathrm{NICHD}$ to MKS. The authors declare that there is no conflict of interest that would prejudice the impartiality of this scientific work.

\section{References}

Baker TG 1963 A Quantitative and Cytological Study of germ cells in human ovaries. Proceedings of the Royal Society of London. Series B. Biological Sciences 158 417-433.

Bramley T 2003 Non-genomic progesterone receptors in the mammalian ovary: some unresolved issues. Reproduction 125 3-15.

Byskov AG, Skakkebaek NE, Stafanger G \& Peters H 1977 Influence of ovarian surface epithelium and rete ovarii on follicle formation. Journal of Anatomy 123 77-86.

Cai Z \& Stocco C 2005 Expression and regulation of progestin membrane receptors in the rat corpus luteum. Endocrinology 146 5522-5532.

Chen HL, Marcinkiewicz JL, Sancho-Tello M, Hunt JS \& Terranova PF 1993 Tumor necrosis factor-alpha gene expression in mouse oocytes and follicular cells. Biology of Reproduction 48 707-714.

Cran DG \& Moor RM 1980 The development of oocytes and ovarian follicles of mammals. Science Progress 66 371-383.

Faddy MJ 2000 Follicle dynamics during ovarian ageing. Molecular and Cellular Endocrinology 163 43-48.

Faddy MJ, Gosden RG, Gougeon A, Richardson SJ \& Nelson JF 1992 Accelerated disappearance of ovarian follicles in mid-life: implications for forecasting menopause. Human Reproduction 7 $1342-1346$. 
Faddy MJ \& Gosden RG 1996 A model conforming the decline in follicle numbers to the age of menopause in women. Human Reproduction 11 1484-1486.

Falkenstein E, Meyer C, Eisen C, Scriba PC \& Wehling M 1996 Full-length cDNA sequence of a progesterone membrane-binding protein from porcine vascular smooth muscle cells. Biochemical and Biophysical Research Communications 229 86-89.

Falkenstein E, Tillmann HC, Christ M, Feuring M \& Wehling M 2000 Multiple actions of steroid hormones - a focus on rapid, nongenomic effects. Pharmacological Reviews 52 513-556.

Fulton N, Martins da Silva SJ, Bayne RA \& Anderson RA 2005 Germ cell proliferation and apoptosis in the developing human ovary. Journal of Clinical Endocrinology and Metabolism 90 4664-4670.

Gosden RG, Laing SC, Felicio LS, Nelson JF \& Finch CE 1983 Imminent oocyte exhaustion and reduced follicular recruitment mark the transition to acyclicity in aging C57BL/6] mice. Biology of Reproduction 28 255-260.

Hirshfield AN 1991 Development of follicles in the mammalian ovary. International Review of Cytology 124 43-101.

Hirshfield AN 1994 Relationship between the supply of primordial follicles and the onset of follicular growth in rats. Biology of Reproduction 50 421-428.

Jefferson W, Newbold R, Padilla-Banks E \& Pepling M 2006 Neonatal genistein treatment alters ovarian differentiation in the mouse: inhibition of oocyte nest breakdown and increased oocyte survival. Biology of Reproduction 74 161-168.

Johnson J, Bagley J, Skaznik-Wikiel M, Lee HJ, Adams GB, Niikura Y, et al. 2005 Oocyte generation in adult mammalian ovaries by putative germ cells in bone marrow and peripheral blood. Cell 122 303-315.

Johnson J, Canning J, Kaneko T, Pru JK \& Tilly JL 2004 Germline stem cells and follicular renewal in the postnatal mammalian ovary. Nature 428 145-150.

Juengel JL, Sawyer HR, Smith PR, Quirke LD, Heath DA, Lun S, et al. 2002 Origins of follicular cells and ontogeny of steroidogenesis in ovine fetal ovaries. Molecular and Cellular Endocrinology 191 1-10.

Kezele P \& Skinner MK 2003 Regulation of ovarian primordial follicle assembly and development by estrogen and progesterone: endocrine model of follicle assembly. Endocrinology 144 3329-3337.

Kondo H, Maruo T \& Mochizuki M 1995 Immunohistochemical evidence for the presence of tumor necrosis factor-alpha in the infant and adult human ovary. Endocrine Journal 42 771-780.

Marcinkiewicz JL, Krishna A, Cheung CM \& Terranova PF 1994 Oocytic tumor necrosis factor alpha: localization in the neonatal ovary and throughout follicular development in the adult rat. Biology of Reproduction 50 1251-1260.

Marcinkiewicz JL, Balchak SK \& Morrison LJ 2002 The involvement of tumor necrosis factor-alpha (TNF) as an intraovarian regulator of oocyte apoptosis in the neonatal rat. Frontiers in Bioscience 7 d1997-d2005.

McNatty KP, Fidler AE, Juengel JL, Quirke LD, Smith PR, Heath DA, et al. 2000 Growth and paracrine factors regulating follicular formation and cellular function. Molecular and Cellular Endocrinology 163 11-20.

Morita Y \& Tilly JL 1999 Oocyte apoptosis: like sand through an hourglass. Developmental Biology 213 1-17.

Morrison LJ \& Marcinkiewicz JL 2002 Tumor necrosis factor alpha enhances oocyte/follicle apoptosis in the neonatal rat ovary. Biology of Reproduction 66 450-457.
Nilsson E, Parrott JA \& Skinner MK 2001 Basic fibroblast growth factor induces primordial follicle development and initiates folliculogenesis. Molecular and Cellular Endocrinology 175 123-130.

Parrott JA \& Skinner MK 1999 Kit-ligand/stem cell factor induces primordial follicle development and initiates folliculogenesis. Endocrinology $1404262-4271$.

Patino R \& Thomas P 1990 Characterization of membrane receptor activity for 17 alpha, 20 beta, 21-trihydroxy-4-pregnen-3-one in ovaries of spotted seatrout (Cynoscion nebulosus). General and Comparative Endocrinology 78 204-217.

Peluso JJ \& Pappalardo A 1998 Progesterone mediates its antimitogenic and anti-apoptotic actions in rat granulosa cells through a progesterone-binding protein with gamma aminobutyric acid A receptor-like features. Biology of Reproduction 58 1131-1137.

Peluso JJ, Fernandez G, Pappalardo A \& White BA 2001 Characterization of a putative membrane receptor for progesterone in rat granulosa cells. Biology of Reproduction 65 94-101.

Peluso JJ, Pappalardo A, Fernandez G \& Wu CA 2004 Involvement of an unnamed protein, RDA288, in the mechanism through which progesterone mediates its antiapoptotic action in spontaneously immortalized granulosa cells. Endocrinology 145 3014-3022.

Pepe GJ, Billiar RB \& Albrecht ED 2006 Regulation of baboon fetal ovarian folliculogenesis by estrogen. Molecular and Cellular Endocrinology 247 41-46.

Pepling ME \& Spradling AC 2001 Mouse ovarian germ cell cysts undergo programmed breakdown to form primordial follicles. Developmental Biology 234 339-351.

Peters H, Byskov AG, Himelstein-Braw R \& Faber M 1975 Follicular growth: the basic event in the mouse and human ovary. Journal of Reproduction Fertilility 45 559-566.

Rajah R, Glaser EM \& Hirshfield AN 1992 The changing architecture of the neonatal rat ovary during histogenesis. Developmental Dynamics 194 177-192.

Richardson SJ, Senikas V \& Nelson JF 1987 Follicular depletion during the menopausal transition: evidence for accelerated loss and ultimate exhaustion. Journal of Clinical Endocrinology and Metabolism 65 1231-1237.

Sawyer HR, Smith P, Heath DA, Juengel JL, Wakefield SJ \& McNatty KP 2002 Formation of ovarian follicles during fetal development in sheep. Biology of Reproduction 66 1134-1150.

Shima JE, McLean DJ, McCarrey JR \& Griswold MD 2004 The murine testicular transcriptome: characterizing gene expression in the testis during the progression of spermatogenesis. Biology of Reproduction 71 319-330.

Sutter-Dub MT 2002 Rapid non-genomic and genomic responses to progestogens, estrogens, and glucocorticoids in the endocrine pancreatic B cell, the adipocyte and other cell types. Steroids $\mathbf{6 7}$ 77-93.

Thau R, Lanman JT \& Brinson A 1976 Declining plasma progesterone concentration with advancing gestation in blood from umbilical and uterine veins and fetal heart in monkeys. Biology of Reproduction 14 507-509.

Tilly JL 1998 Molecular and genetic basis of normal and toxicantinduced apoptosis in female germ cells. Toxicology Letters 102-103 497-501.

Received 26 May 2006

First decision 25 July 2006

Accepted 23 August 2006 